\title{
Thermodynamic analysis of an integrated gas turbine power plant utilizing cold exergy of LNG
}

\author{
E. N. Krishnan', N. Balasundaran' ${ }^{2}$ R. J. Thomas ${ }^{3}$ \\ ${ }^{1}$ Department of Mechanical Engineering \\ Saintgits College of Engineering, Kottayam, 686532, India, \\ Phone: +91 9446497892 \\ ${ }^{2}$ Department of Mechanical Engineering \\ Viswajyothi College of Engineering and Technology, Ernakulam, 686670, India \\ ${ }^{3}$ Department of Mechanical Engineering, TKM College of Engineering \\ Kollam, 695004, India \\ easwaranme@gmail.com
}

\begin{abstract}
The main concerns in energy from petroleum-based fuels are the scarcity, cost, and pollution the fuels. Now, natural gas is considered as a better alternative. The process of converting natural gas into liquefied natural gas (LNG) is highly energy intensive and consumes about $10-15 \%$ of the total energy spent on natural gas production. Novel methods for regasification of LNG (converting back to NG) exist and are being used in various applications; mainly in power generation and refrigeration. One such method in power generation, the cold associated with LNG (cold exergy) can be utilized efficiently for improving the performance of power plants based on the Brayton cycle by precooling the working fluid. The study investigated such a possibility of precooling the inlet working fluid and to bring out the various factors influencing the overall efficiency of the power plant and regasification of LNG. Exergy analysis is the tool used for this study. The combined power plant is modeled using Aspen Hysys process simulation tool, and the results show that there is $35-135 \%$ improvement in the exergy efficiency of the power plant. This study also intends to find a suitable working fluid based on the objective functions such as exergy efficiency of the power plant and a regasification parameter (mass flow ratio). The gas turbine cycle gives maximum exergy efficiency when air is used as working fluid and Helium is the best working fluid candidate where regasification is the prime objective. Helium can gasify LNG about ten times more than other three working fluids
\end{abstract}

Keywords: Liquefied natural gas; regasification; power generation; Brayton cycle, exergy analysis.

\section{INTRODUCTION}

Natural gas (NG) is now considered as an alternative to the conventional fuels owing to the latter's issues like limited availability, increased cost and higher pollution. NG is found in deep underground rock formations or associated with other hydrocarbon reservoirs in coal beds and as methane clathrates. However, it is found only in specific areas and most of the reserves are in the Middle East, Russia and the United States [1-3]. Therefore, for distributing it around the globe, it has to be transported over long distances. It can be transported to customer's location in gaseous form (CNG), liquid form (LNG), solid form (Hydrates) and also in the form of electricity. Though there exist different methods for transportation of $\mathrm{NG}$, it is highly economical and easier to convert 
$\mathrm{NG}$ to liquid and then to transport over long distances. $\mathrm{NG}$ needs to be cooled to about $-162^{\circ} \mathrm{C}(110$ $\mathrm{K}$ ) for converting into liquefied natural gas (LNG). In liquid form, natural gas takes up only 1/600 of the volume of its gaseous state and therefore, can be easily stored and transported to places in bulk quantities. However, for the final use LNG need to be converted back to NG and the process is termed as 'Regasification.'

Conversion of NG to LNG is a huge energy-intensive process and it needs an approximate $900 \mathrm{kWh} / \mathrm{kg}$ which is about $3 \mathrm{MJ} / \mathrm{Kg}$ [1]. A part of this energy will be stored in the form of chemical exergy/available energy and remaining will be dissipated as heat during the process of liquefaction. It is estimated that about $0.25 \mathrm{Kwh} / \mathrm{Kg}(830 \mathrm{KJ} / \mathrm{Kg})$ of energy can be recovered from the cold LNG when it is converted back to NG [1,2]. Considering the handling capacity of various LNG plants across the world (Global regasification capacity estimated as 851 million tonnes per annum) this is significant, hence utilizing this cold exergy sustainably will reduce its environmental impact and additional energy requirement of regasification.

The type of the regasification technique used depends on many factors such as the location of the plant, conditions of surroundings, local rules and regulations, etc [1-3]. Presently, open rack vaporizers, submerged combustion vaporizers and ambient air vaporizers [1] are the commonly used regasification techniques. However, in all these methods, the energy spend for liquefying NG is wasted entirely (or unutilized). There are different ways in which a significant portion of this energy can be utilized in various types of application [4-6].

There exists a wide scope of utilizing the cold exergy associated with LNG regasification in power generation [1-3]. Researchers have suggested a number of methods for utilizing this cold exergy and two of them are (i) the direct expansion of LNG: in which LNG is pumped to very high pressure and then expanded to the required pressure limits. This system has the lowest efficiency as it utilizes only the physical exergy of LNG [5-7]. (ii) The use of LNG as a heat sink for the Rankine based power plants [8-10].

There are many literature investigating the suitability of organic working fluids for Rankine based power plants. Macro et al. found out ethane, propane and Propylene as ideal candidates for Rankine cycle, based on specific work output [10-14] But most of the working fluids freeze when it is in contact with LNG at the condenser [13]. A closed gas turbine cycle has the capability of entirely utilizing the cold associated with LNG since it requires only a cooling medium to reject heat from the turbine exhaust. Thus, an efficiently designed closed gas turbine (GT) cycle can utilize the full temperature span of LNG, thus exploiting its total cooling capacity. The thermal efficiency of a power plant doesn't depend on the working fluid, but it depends on the heat source and heat sink temperature, which in turn depends on the properties of working fluid. Therefore, there is a possibility to enhance the regasification and efficiency by choosing right working fluid [15-17].

This study aims to investigate the possibility of utilizing the cold associated with LNG in regasification for enhancing the performance of a Brayton cycle-based (GT) power plants and the role of different working fluids on regasification performance. It may also be noted that the regasified LNG is eventually used in the power plants as their fuel. The identified performance parameters for power generation and regasification of LNG are exergy efficiency (GT plant performance), mass flow ratio (regasification performance), and UA ratio (Thermal size/area of heat exchangers). 


\section{SYSTEM ANALYSIS AND METHODOLOGY}

The configuration selected for the study, which is a closed regenerative Brayton cycle, is shown in Figure 1. There are three heat exchangers employed as an intercooler, reheater, and condenser in the configurations along with the compressor and turbine. The combustion section is not shown in the diagram. The working fluid enters the compressor and gets compressed to the required pressure (process 6-1). Then it passes through a heat exchanger (HX1) where it absorbs heat from turbine exhaust gas (regeneration process 1-2). The preheated gas is again heated up in another heat exchanger (HX2) by the heat of combustion (process 2-3). The change of state for the combustion fluid is from 9-10. Finally, it is expanded inside the turbine (Expander) to atmospheric conditions (process 3-4) and thereby producing work.

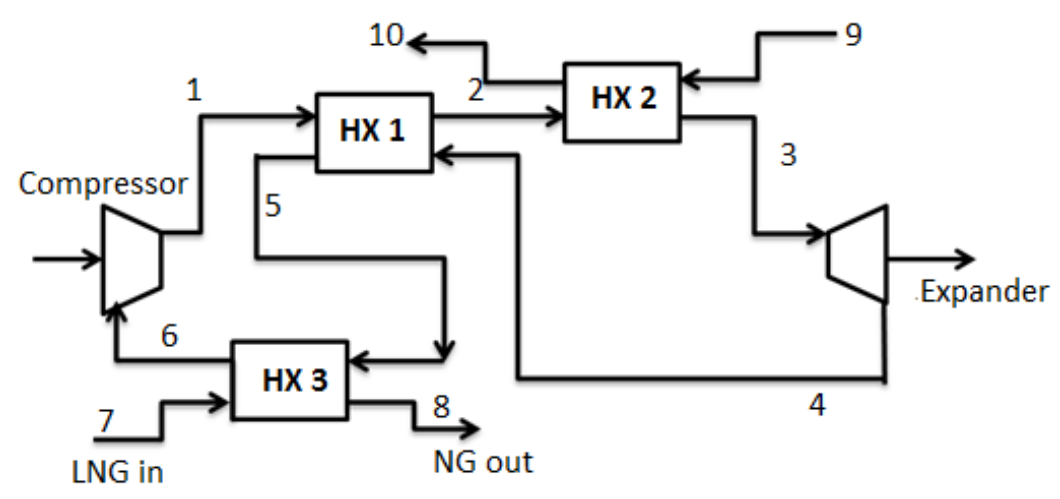

Figure 1. Schematic diagram of a closed regenerative Brayton cycle with LNG inlet cooling.

The exhaust from the turbine always contains some amount of heat. In the regenerative configuration, some part of this heat is utilized for preheating the compressed gas in HX1 (process 4-5). The LNG is converted to NG (in HX3) in the process of pre-cooling the working fluid (process 5-6) before being fed to the compressor to reduce the work of compression.

The exergy approach is employed in this study for the analysis of the Brayton cycle. Exergy has proved to be a useful tool to evaluate and analyze the design and operation of various systems. The First Law of thermodynamics is concerned only with the conservation of the quantity of energy and cannot determine the degradation in the quality of energy. In the comparison, exergy analysis provides a more accurate representation regarding conversion as compared with the energy-based analysis. Exergy analysis has the potential to identify the amount of thermodynamic irreversibility associated with the overall cycle as well as with each component. Exergy analysis brings together the First and Second Law of thermodynamics and describes the quantity and the quality of the energy utilization [18-20].

$$
\sum_{j} Q j\left(1-\frac{T o}{T i}\right)-\sum \dot{W}+\sum_{i n} \dot{E} x_{m a s s}-\sum_{o u t} \dot{E} x_{m a s s}-\dot{E} x_{d e s t}=0
$$

In the Equation 1, the term $\Sigma_{j} Q_{j}\left(1-\frac{T_{i}}{T_{j}}\right)$ represents the exergy transfer associated with heat. Exergy accompanying the work interaction $(W)$ equals the electrical or mechanical work itself. The term $\Sigma_{\text {in }} E_{x_{\text {mass }}}-\Sigma_{\text {ont }} E_{x_{\text {mass }}}^{*}$ represents the resultant exergy transfer associated with mass flow into and out of the control volume. The flow exergy is expressed as:

$$
\dot{E} x_{\text {mass }}=\dot{m} \times e x=\dot{m} \times\left(\left(h-h_{0}\right)-T_{0 \times}\left(s-s_{0}\right)\right)
$$


Where, $\dot{m}$ represents the mass flow rate $(\mathrm{kg} / \mathrm{s})$; ex represents the exergy per unit mass $(\mathrm{kJ} / \mathrm{kg}), h$ and $s$ correspond to the specific enthalpy and specific entropy of the fluid respectively. $h_{0}$ and $s_{0}$ represent the enthalpy and entropy at the reference state $\left(T_{0}, P_{0}\right)$ respectively. For this analysis, the atmospheric condition is taken as the reference state $\left(T_{0}=300 \mathrm{~K}\right.$ and $P_{0}=1.01325$ bar).

The exergy balance equation is given as Equation. (1) is applied across the cycle shown in Fig. 1, and it gives:

$$
\begin{aligned}
& \sum \dot{W}_{\text {comp }}-\sum \dot{W}_{\text {Turbine }}+\sum_{\text {in }} \dot{E} x_{H_{\text {Heat }}{ }_{\text {source }}}-\sum_{\text {out }} \dot{E} x_{\text {Heat }- \text { source }}+ \\
& \sum_{\text {in }} \dot{E} x_{L N G}-\sum_{o u t} \dot{E} x_{L N G}-\sum \dot{E} x_{d e s t}=0
\end{aligned}
$$

Therefore, the exergy efficiency of the cycle is defined as:

$$
\eta_{E X}=\frac{\sum \dot{W}_{\text {Turbine }}-\sum \dot{W}_{\text {Compressor }}}{\left(\sum_{\text {in }} \dot{E} x_{\text {Heat }} \text { source }_{-}-\sum_{\text {out }} \dot{E} x_{\text {Heat }} \text { source }_{\text {son }}\right)+\left(\sum_{\text {in }} \dot{E} X_{L N G}-\sum_{\text {out }} \dot{E} x_{L N G}\right)}
$$

The numerator of Equation (4) denotes the net-work available in the cycle, which is the work produced in the turbine minus the work expended for the compression process. The net-heat input to the system is represented by the first term of the denominator; while its second term denotes the exergy input via LNG regasification. It may be noted that the exergy efficiency of the cycle may also be defined in terms of the exergy destruction by combining Equation 3 and 4. The exergy destruction in the cycle $E_{\text {dest }}$ represents the sum of exergy destructions in all its constituting components of the cycle.

The regasification parameter or flow ratio is defined as the ratio of the mass of LNG regasified to the mass of working fluid of the power cycle and which is estimated by energy balance across the LNG inlet precooler as shown in equation 5.

For the study, the different parameters are set as follows: Efficiency of the compressor and turbine as $75 \%$, Effectiveness of each of the heat exchangers as 0.90 . The suction and discharge pressure of the compressor as 1.013 and 8 bar. It is assumed that the combustion happens elsewhere and only the heat of combustion is added to the cycle. It is assumed that LNG is getting vaporized to $298 \mathrm{~K}$ (at atmospheric pressure) in the condenser. The mass flow rate of working fluid is taken 1 $\mathrm{kg} / \mathrm{s}$. The composition of LNG adopted for this study is given in Table 1 .

The performance of the selected modified Brayton cycle is compared with that of a base cycle. The base cycle is as similar as the cycle shown in Figure 1; however, it does not have the cooling process using LNG regasification. For the base cycle, the working fluid is Air. All other operating parameters remain the same as that of the modified Brayton cycle with the option LNG regasification.

Table 1. Composition of Liquefied Natural Gas [1]

\begin{tabular}{ll}
\hline Component & Mole fraction \\
\hline $\mathrm{N}_{2}$ & 0.0007 \\
$\mathrm{CH}_{4}$ & 0.8877 \\
$\mathrm{C}_{2} \mathrm{H}_{6}$ & 0.0754 \\
$\mathrm{C}_{3} \mathrm{H}_{8}$ & 0.0259 \\
$\mathrm{n}-\mathrm{C}_{4} \mathrm{H}_{8}$ & 0.0056 \\
$\mathrm{i}-\mathrm{C}_{4} \mathrm{H}_{8}$ & 0.0045 \\
$\mathrm{n}-\mathrm{C}_{5} \mathrm{H}_{12}$ & 0.0001 \\
$\mathrm{i}-\mathrm{C}_{5} \mathrm{H}_{12}$ & 0.0001 \\
\hline
\end{tabular}


The literature has suggested some potential working fluids that can be used in such power cycles $[15-18,20]$ and the working fluids selected for this study are helium, argon, nitrogen, and air. The first criterion for the selection of a suitable fluid is the critical temperature of the working fluid should not be much higher than the lowest cooling temperature. It is considered that when using LNG for cooling, the lowest temperature is $140 \mathrm{~K}$. Furthermore, the fluid selected must be nontoxic, non-corrosive and non-flammable [14]. The relevant thermodynamic properties of the selected working fluids are given in Table 2.

Table 2. Relevant properties of the different working fluids selected [21]

\begin{tabular}{|c|c|c|c|c|c|c|}
\hline Fluid & $\begin{array}{c}\text { Molecul } \\
\text { ar mass }\end{array}$ & $\begin{array}{l}\text { Critical } \\
\text { Temperatur } \\
\text { e (K) }\end{array}$ & $\begin{array}{l}\text { Critical } \\
\text { pressure } \\
\text { (bar) }\end{array}$ & $\begin{array}{c}\text { Ratio of } \\
\text { Specific } \\
\text { Heat y } \\
(\mathrm{kJ} / \mathrm{kg} \text { - } \\
\mathrm{K})\end{array}$ & $\begin{array}{l}\frac{8-1}{8} \\
(1.013 \\
\text { bar })\end{array}$ & $\begin{array}{l}\frac{y-1}{y} \\
(8 \text { bar })\end{array}$ \\
\hline Argon & 39.94 & 150.86 & 48.98 & 0.51 & 0.4060 & 0.3997 \\
\hline Nitrogen & 28.01 & 126.20 & 33.98 & 1.39 & 0.2986 & 0.2527 \\
\hline Helium & 04.00 & 5.20 & 2.275 & 1.66 & 0.3999 & 0.3998 \\
\hline Air & 28.96 & 132.52 & 37.66 & 1.40 & 0.3056 & 0.2497 \\
\hline
\end{tabular}

The aim of this study is not only to determine the improvement in the performance of such power plants with regasification facility but also to bring out the suitable working fluid which is capable of regasifying more LNG for the same operating conditions [21]. The target is also to identify the various influencing parameters that affect the plant performance and to bring out the relative influence of one parameter over the other. The exergy-based analyses are carried out and the variation in performance indicators such as exergy efficiency, LNG vaporization rate, efficiency and sizes of heat exchangers, etc. are analyzed.

\section{Validation of Simulation Tool}

The GT power plant modeled using Aspen Hysys V8, Process simulation tool. Component validation of the simulation tool has done using the GT power plant data available in the literature [22]. The percentage of deviation from the actual plant data and simulation model is shown in Table 3.

Table 3. Component validation of Simulation tool

\begin{tabular}{ll}
\hline Parameter & $\begin{array}{l}\text { Maximum } \\
\text { deviation }(\%)\end{array}$ \\
\hline Temperature & 0.4 \\
Pressure & 0.01 \\
Compressor efficiency & 0.83 \\
Expander efficiency & 0.95 \\
Power output & 3.39 \\
\hline
\end{tabular}

The maximum deviation among all the parameters is found to be less than $5 \%$. Therefore, the simulation tool is capable of giving accurate results for GT power plants. 


\section{RESULTS AND DISCUSSIONS}

The configuration has been mathematically modeled in Aspen HYSYS and the analysis has been performed using four different working fluids. The effect on overall efficiency of the cycle, exergy destruction in individual components, sizes of the heat exchanger and the amount of LNG regasified are investigated and calculated.

\section{Overall Power Cycle Performance}

The variation in exergy efficiency of the modified configuration when using different working fluids is shown in Figure 2. The efficiency of the base cycle without regasification facility is plotted for comparison. Figure 2 shows that performing LNG regasification in Brayton based power plant has a significant influence on improving the overall efficiency of the power plant. When employing LNG regasification, there is a minimum improvement of about $35 \%$ as compared to the base cycle (in case of helium). The maximum improvement is nearly about 135\% (when using air as the fluid). The figure also shows that proper selection of working fluid is essential as the exergy efficiency does not remain the same for all the working fluids. The Exergy efficiency of power plant depends on the work output of the expander and the work input to the compressor. At specified component efficiencies, the net-work primarily depend on the Inlet temperature for both cases. The lowest turbine inlet temperature and highest compressor inlet temperatures for same pressure ratio are obtained for Helium and which in turn reduce the plant exergy efficiency.

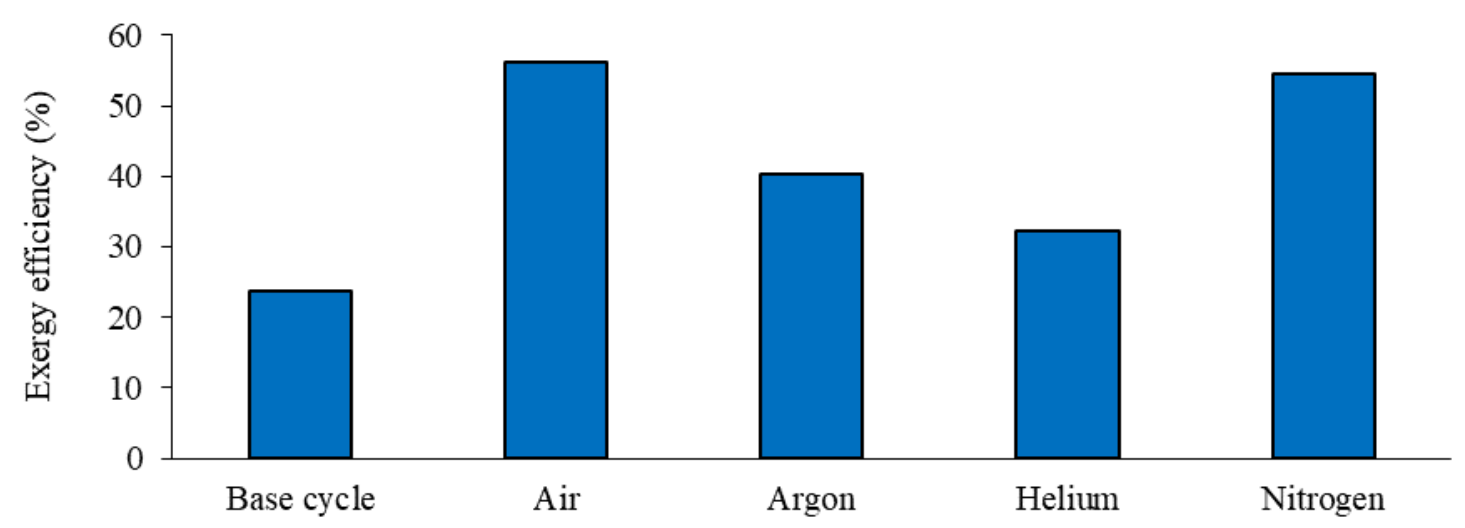

Figure 2. Exergy efficiency of the Brayton based cycle for selected working fluids.

When using air as the working fluid, it provides the highest exergy efficiency (56\%). Configuration using nitrogen provides almost equal efficiency. This finding justifies the reason for using air as working fluid in the conventional Brayton cycle-based power plants. The lowest exergy efficiency is resulted while using helium (32.3\%). The reason for lower exergy efficiency for certain fluids when used as the working fluid can be explained by their ratio of specific heats $(\gamma)$ and specific heats.

$$
\left(\frac{T_{2}}{T_{1}}\right)=\left(\frac{P_{2}}{P_{1}}\right)^{\left(\frac{\gamma-1}{\gamma}\right)}
$$

In an isentropic process, for the same inlet temperature and pressure change $(\Delta p)$, working fluids having a smaller value of the property $(\gamma-1) / \gamma$ will show a smaller temperature change $(\Delta T)$ as given in Equation. 2. In the case of the Brayton cycles studied here, the expansion and compression of working fluid are close to the isentropic process. For the same pressure ratio, during the isentropic expansion process fluids with a smaller value of $\left(\gamma^{-1}\right) / \gamma$ will cool down to a lower temperature 
when inlet temperature is held constant; thereby, increase the cycle efficiency. In the compression process, fluids with a smaller value of $(\gamma-1) / \gamma$ (for the same pressure ratio) will result in lower temperature change. Therefore, in the regenerative heat exchanger (HX1), the gas from the turbine exhaust can be cooled to a much lower temperature. This will eventually improve the overall efficiency. Table 1 shows the values of the parameter $(y-1) / y$ for different working fluids in a specified operating condition. The table shows that the value corresponding to air and nitrogen are the least. These findings agree with that of the earlier literature [3]. The specific heat values for He and $\mathrm{Ar}$ are 5.19 and $0.520 \mathrm{KJ} / \mathrm{Kg} \mathrm{K}$, which means, the turbine inlet temperature (LNG precooling) for both the working fluids are different and the inlet temperature is low in case of Ar cycle compared to He cycle. This also improves the efficiency of Ar cycle compared to He cycle.

It may be noted that when taking the exergy balance, the exergy destructions in all the components added together with the useful exergy, should give the total exergy supplied into the system (100\%). The maximum exergy efficiency (when using air) is only about $56 \%$. It would be interesting to find out in which all components, the remaining exergy is being lost. Therefore, a study has been performed to identify the exergy destruction in each component of the cycle. This also will help to identify the critical components in the cycle. The exergy destruction in the five components of the cycle, viz. compressor, expander and the three heat exchangers, HX1 (regenerative one), HX2 (Heat source one) and HX3 (LNG inlet cooler) are depicted in Figure 3. From the figure, it may be noted that the exergy destructions in compressor and heat exchangers (except that for LNG regasification), are not changing much with a change in working fluid.

However, the variation is significant in case of the expander and the LNG regasification heat exchanger (HX3), which is the addition of the modified configuration. The amount of exergy destructed in expander is a direct function of the isentropic efficiency of the expander. Along with the efficiency, other parameters that affect the performance of the expander are the operating temperature and mass flow rate through the expander. For the same heat input, the temperature of working fluid at the inlet of the expander (3) is low for Helium and which is closer to dead state compared to other working fluids. It may be noted that the pressure ratio has not been varied in this study.

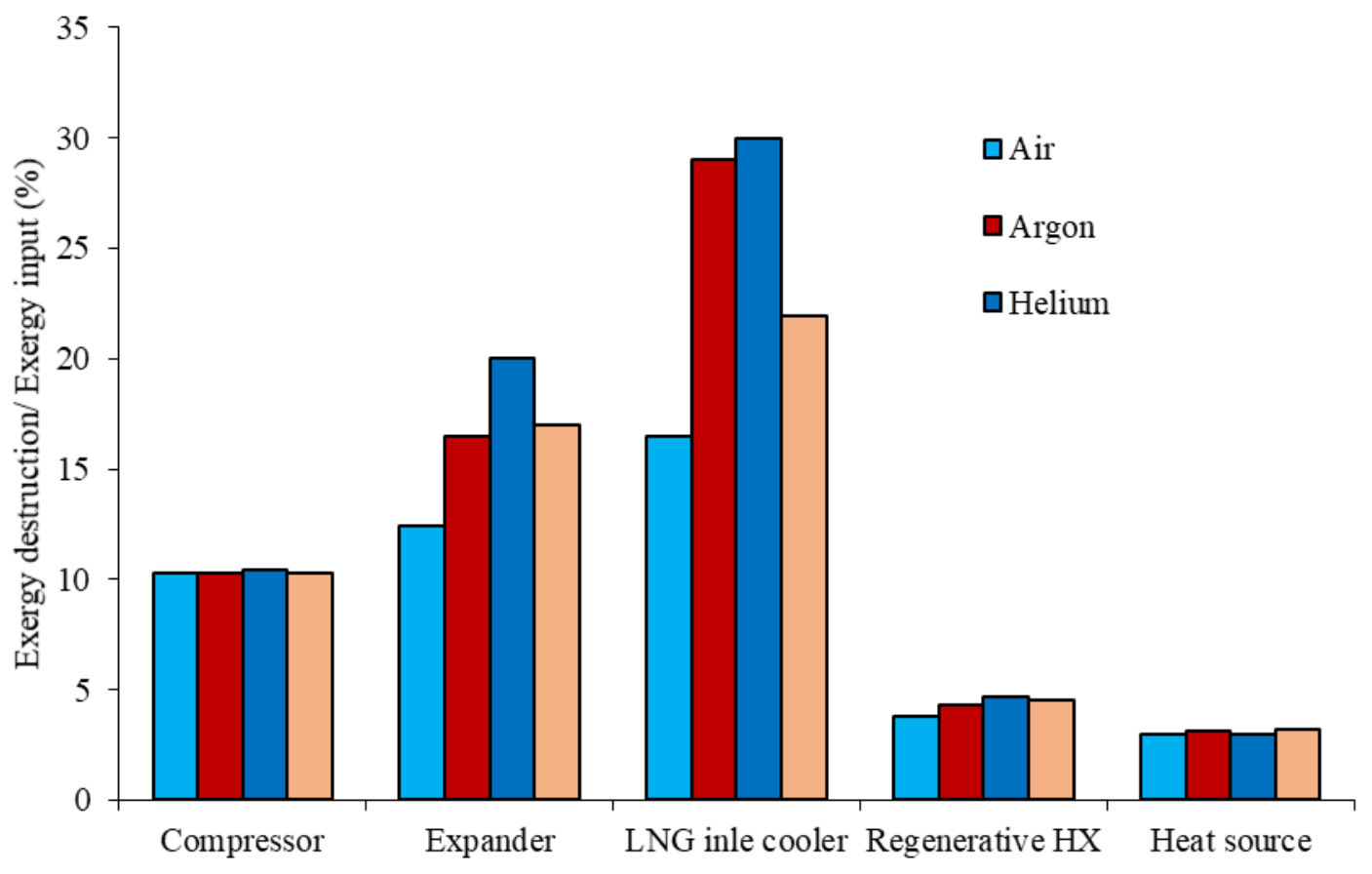

Figure 3. Exergy destruction in each component for selected working fluids. 


\section{Performance of Heat Exchangers}

The reason for variation in exergy destruction in LNG regasification heat exchanger (HX 3) with a change in working fluid is investigated further. It has been found that the amount of heat transferred in regasification (heat duty of regasification heat exchanger) in each case is different.

The heat transfer capability of a heat exchanger may be depicted through its rational exergy efficiency. Using Equatiiion.3, the rational exergy efficiency of the regasification heat exchanger is computed for each working fluid and is plotted in Figure 4.

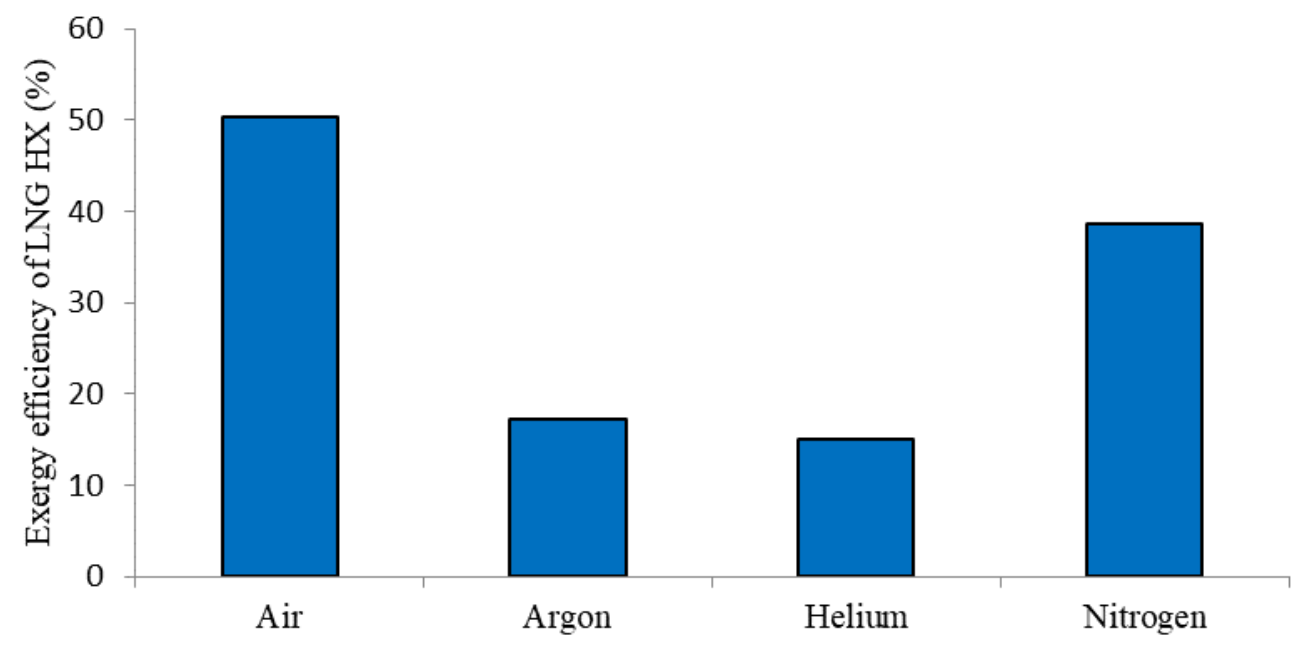

Figure 4. Rational Exergy efficiency LNG regasification Heat exchanger

Figure 4. shows that for each working fluid the exergy efficiency is different; The maximum is for air (about 50\%) and the minimum is for Helium (about 17\%) and then Argon (about 18\%). Being the main constituent of air, nitrogen gives a value near to that of air. A significant portion the exergy is destructed in cases of Helium and Argon as evident from Figure 3 and 4.

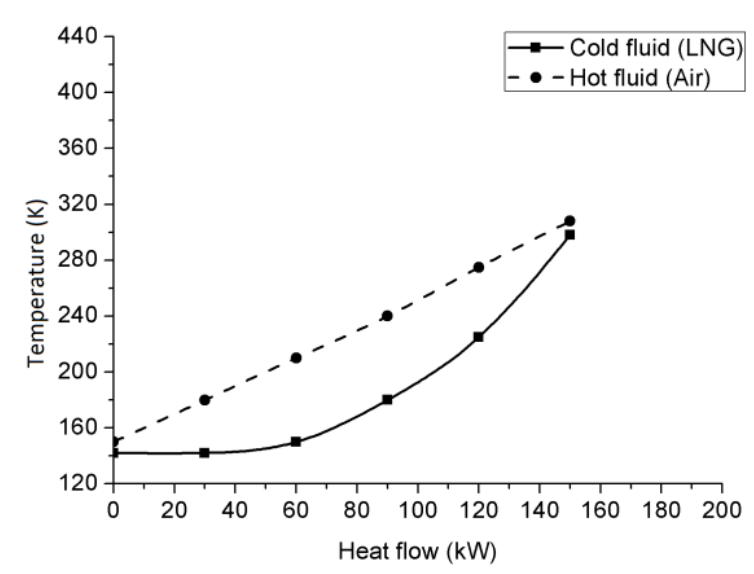

a. Air

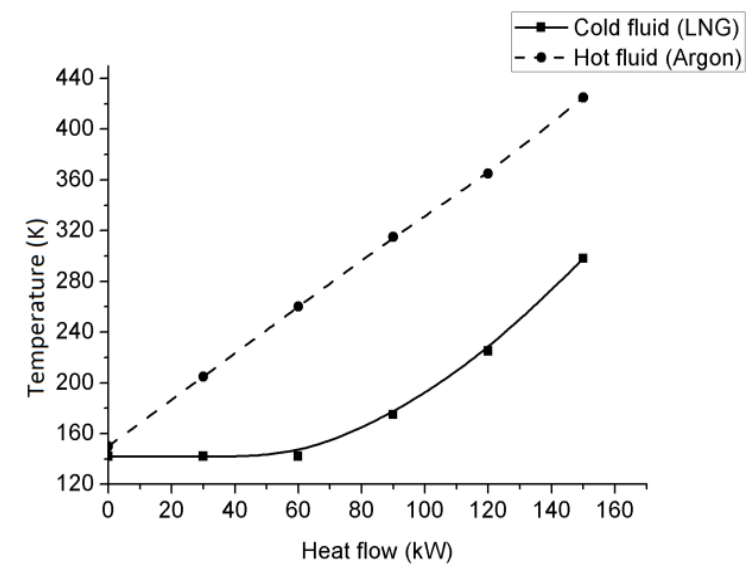

b. Argon 


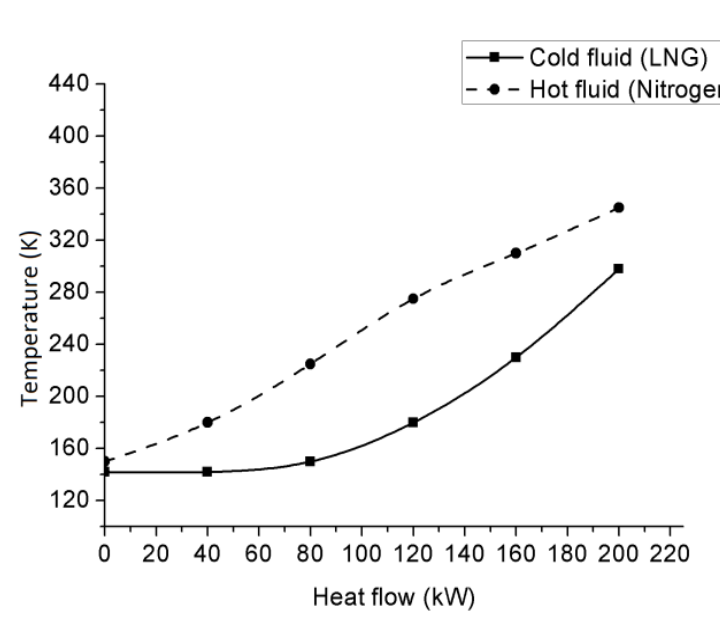

b. Nitrogen

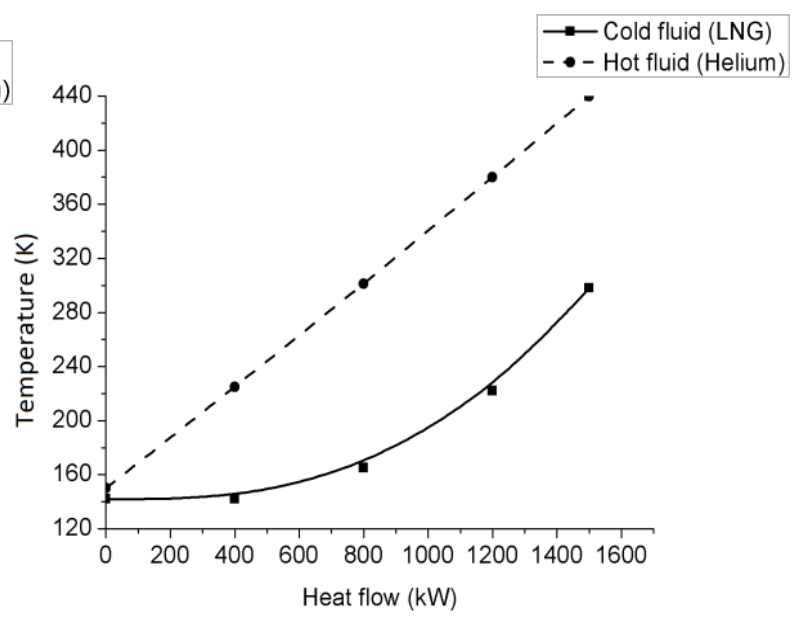

d. Helium

Figure 5. Heat transfer profile of LNG regasification heat exchanger.

One of the primary reasons for exergy destruction in any heat exchanger is due to transfer between a finite temperature difference between hot and cold streams. The imbalance between the mass flow rates of LNG and working fluid leads to widening of temperature profile [18]. For transferring the same amount of heat, helium regasifies almost twice the amount of LNG and this higher imbalance is the reason for exergy destruction. The exergy destruction will be the minimum if the temperature gap $(\Delta \mathrm{T})$ between the hot and cold fluids is small. The heat transfer profiles of the heat exchanger (heat versus temperature: Q-T curve of HX3) plotted in Figure 5 (a,b,c \& d) would give a better picture of this separately for the different working fluids.

Air shows the minimum exergy destruction as the area enclosed between hot and cold fluid is the least when compared to the other fluids. The next one is the case using nitrogen. It may be noted from the figure that the enclosed area is much significant in the case of argon and helium. Along with the thermodynamic performance, another important parameter for the heat exchanger is its size, which has a direct impact on the capital investment as well as on the size of the plant. It indicates the thermal size of heat exchangers and also can be taken as an indicator for assessing the physical size. The UA of heat exchangers can be estimated using Equation 6.

$$
Q=U A \times L M T D
$$

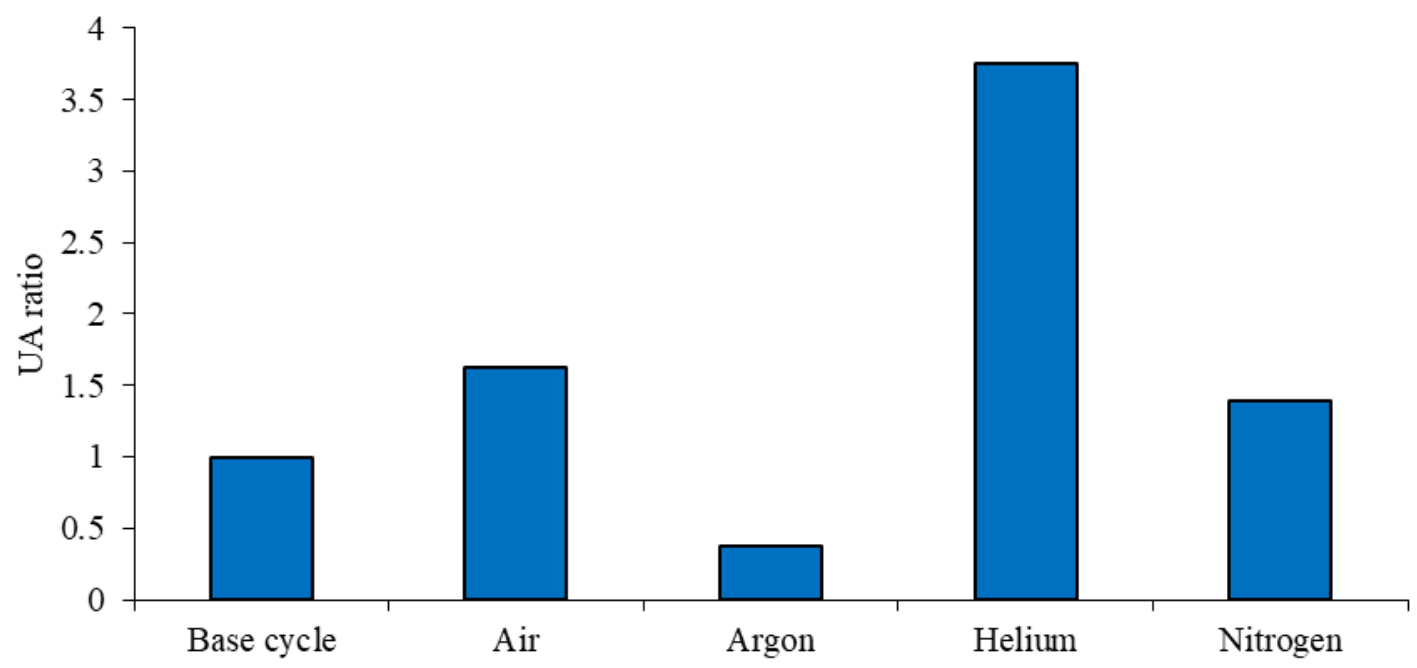

Figure 6. UA ratio for different working fluids. 
Figure 6 shows that the UA ratio is maximum while using helium as working fluid; indicating that the heat exchanger is big. It may be noted that out of all selected working fluids, helium has the highest specific heat capacity $\left(C_{p}\right) . C_{p}$, being the amount of heat required to raise the temperature by one degree, under low values of $L M T D$, it demands more surface area to transfer the same amount of heat. On the other hand, argon having the least specific heat $(0.5 \mathrm{~kJ} / \mathrm{kg}-\mathrm{K})$, has the least surface area. Nitrogen and air have almost similar specific heat values, the sizes of their regasification heat exchangers are comparable.

\section{Variation in Amount of LNG Regasified}

Another significant parameter is the quantity of LNG that can be regasified using a particular working fluid. This parameter is nondimensionalized and presented as mass flow ratio, which is defined as the ratio of the mass of LNG regasified to the mass of working fluid of cycle. In each case, the amount of LNG that can be regasified is determined; this is calculated such that the latent heat, as well as the sensible heat up to $298 \mathrm{~K}$ temperature, is supplied. Figure 7 shows the variation of mass flow ratio while using different working fluids.

It may be noted from Figure 7 that the maximum amount of LNG regasification (1.9 times) happens while using helium as the working fluid; which is almost double the flow rate of working fluid. For all other working fluids, the value is near about 0.2 to 0.3 times the flow rate of working fluid. This difference has been investigated further. The regasification rate (or the amount of LNG vaporized in the process) depends on heat rejection from working fluid to the LNG in the regasification heat exchanger. The amount of heat rejection from the working fluid is a direct function of its mass flow rate, the fluid property specific heat and the temperature difference $\left(Q=\dot{m} c_{p} \Delta T\right)$.

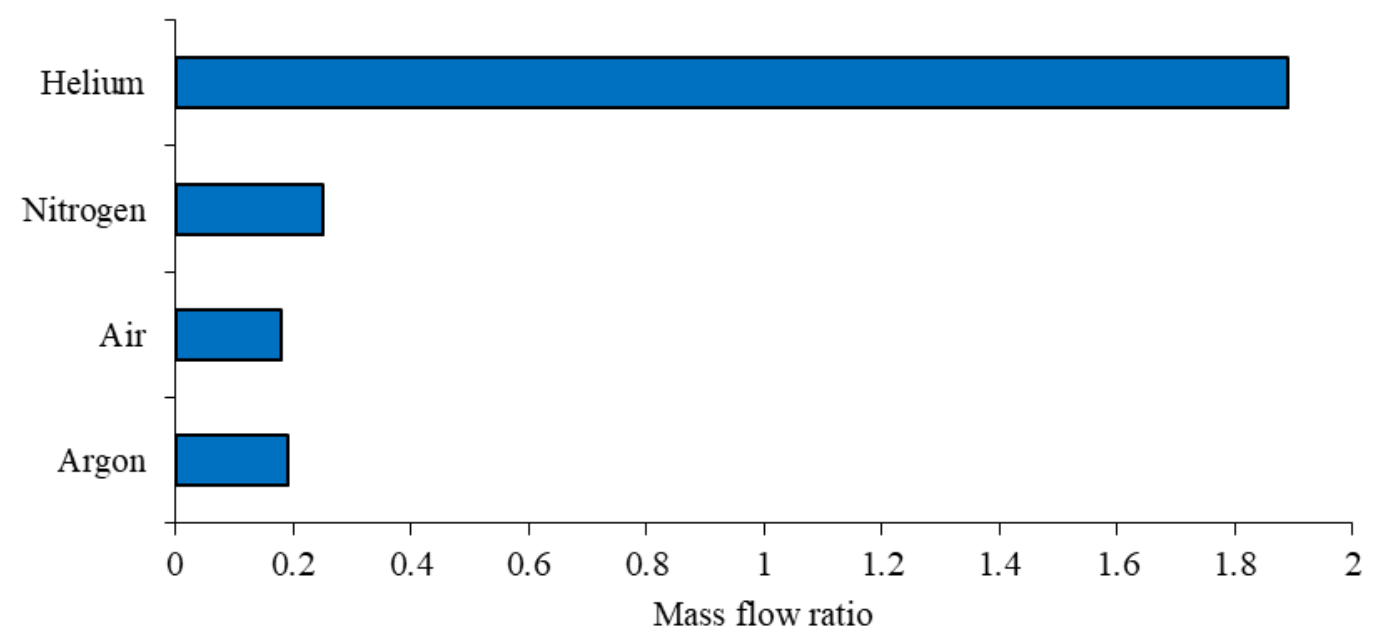

Figure 7. Mass flow ratio for different working fluids.

The mass flow rate being constant throughout the cycle has no significant impact. However, the value of specific heat and temperature of working fluid have a prominent role to play. The input temperature of the working fluid to the regasification heat exchanger is determined by the performance of the upstream component which is the regenerative heat exchanger (HX1). Among the selected working fluids, helium has highest inlet temperature, $448 \mathrm{~K}$ (as evident from Figure 4) and the highest specific heat value. Therefore, considering the more considerable heat rejection, it would vaporize more quantity of LNG. Even though the input temperature of Argon is more than that of Helium, the vaporization rate of Argon is much lower than that of Helium. This is due to the very low specific heat value of Argon $(0.5 \mathrm{~kJ} / \mathrm{kg}-\mathrm{K})$. For the other two fluids, (nitrogen and air) the input temperatures are comparatively less. Some previous literature also suggests helium as a 
working fluid for combined regasification-power generation terminals. However, this is at the expense of plant performance [23-25].

\section{CONCLUSIONS}

This study investigated the efficiency of a modified Brayton configuration which is capable of regasifying the liquefied natural gas (LNG) in power production. Steady-state simulations of the power plant have been developed in Aspen HYSYS. The exergy-based approach has been employed to identify the irreversibility associated with the plant, and it's influencing parameters. The working fluids considered are air, argon, nitrogen, and helium.

The major conclusions from this study are

- The cold Exergy of LNG can improve the performance of a GT power plant more than 135 $\%$. This is achieved as the compressor inlet of working fluid is brought down through regasification of LNG and thereby reducing the energy consumed in the compressor.

- The heat capacity of working fluid plays a significant role in regasification performance and Exergy efficiency. The working fluid candidate with lower heat capacity can attain a very low temperature at the compressor inlet, however the quantity of LNG regasified will be less. Therefore, selection of working fluid is very critical, and it depends on our primary objective (GT plant efficiency or regasification).

- When keeping the thermodynamic performance (exergy efficiency) as the objective function, air or nitrogen is found to be the best working fluid.

- Helium is an ideal working fluid to regasify vast quantity of LNG (preferably in regasification terminals) for the Brayton cycle because of its high specific heat, resulting in less volume flow rate and a higher flow ratio when compared to the use of air or nitrogen.

- The low exergy efficiency of Argon is due to the high value of the ratio of heat capacities at high pressures compared to Air or Nitrogen. However, if the size of the plant (which indirectly is a function of capital cost) is a major concern Argon is the suitable working fluid candidate.

A detailed investigation into the irreversibility associated with each component as well as the overall configuration helped to derive the underlying reasons. The practical challenges such as heat loss, handling of low temperatures and requirements such as additional storage containers may increase the principal cost. Therefore, more detailed analysis is needed to estimate the potential of regasification-integrated gas turbine power plants.

\section{ACKNOWLEDGMENT}

We gratefully acknowledge the support given by Dr. Rohan Dutta of Department of Energy and Process Engineering, NTNU, Trondheim, Norway in the simulation studies on Aspen HYSYS. 


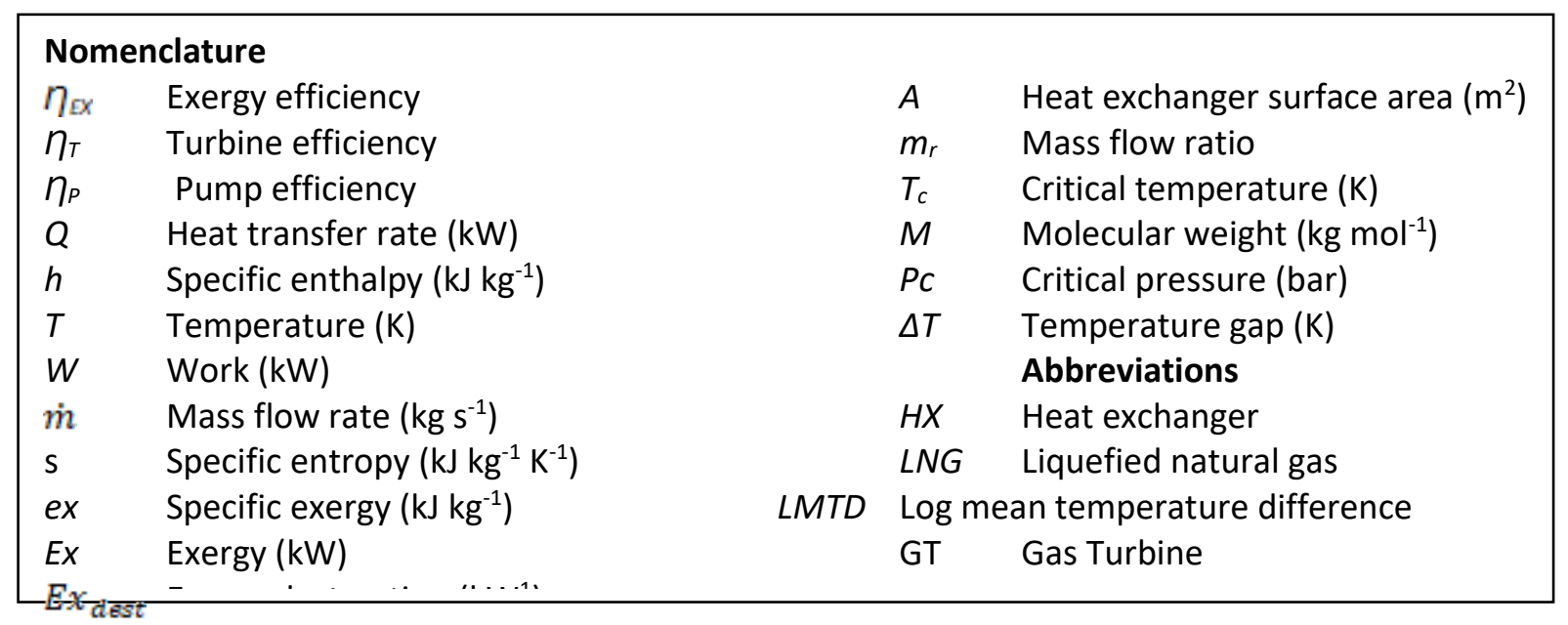

\section{APPENDIX}

The work also provides simulation data in Table 4 which may useful to the researchers in this area of research.

Table 4: Simulation data of modelled GT power plant-regasification facility Working fluid: Helium

\begin{tabular}{lllll}
\hline \hline & Temperature $\left({ }^{\circ} \mathrm{C}\right)$ & Pressure $(\mathrm{kPa})$ & Mass flow $(\mathrm{kg} / \mathrm{hr})$ & Vapor fraction \\
\hline \hline 1 & 142.6 & 800 & 3600 & 1 \\
2 & 327.5 & 800 & 3600 & 1 \\
3 & 800 & 800 & 3600 & 1 \\
4 & 347.5 & 101.3 & 3600 & 1 \\
5 & 162.6 & 101.3 & 3600 & 1 \\
6 & -122.5 & 101.3 & 3600 & 1 \\
7 (LNG in & -132.5 & 550 & 7007 & 0 \\
8 (LNG out) & 15 & 500 & 7007 & 1 \\
\hline \hline
\end{tabular}

\begin{tabular}{|c|c|c|c|c|}
\hline & & Work input $(\mathrm{kW})$ & Work output $(\mathrm{kW})$ & Heat supplied (kW) \\
\hline Compressor & & 1375 & & \\
\hline Expander & & - & 2352 & - \\
\hline $\begin{array}{l}\text { Heat } \\
\text { (Source) }\end{array}$ & supplied & - & - & 2455 \\
\hline
\end{tabular}

Working fluid: Nitrogen

\begin{tabular}{llllll}
\hline \hline & $\begin{array}{l}\text { Temperature } \\
\left({ }^{\circ} \mathrm{C}\right)\end{array}$ & Pressure $(\mathrm{kPa})$ & $\begin{array}{l}\text { Mass } \\
(\mathrm{kg} / \mathrm{hr})\end{array}$ & flow & Vapor fraction \\
\hline \hline 1 & 40.9 & 800 & 3600 & 1 \\
2 & 446.6 & 800 & 3600 & 1 \\
3 & 800 & 800 & 3600 & 1 \\
4 & 467 & 101.3 & 3600 & 1 \\
5 & 60.9 & 101.3 & 3600 & 1
\end{tabular}




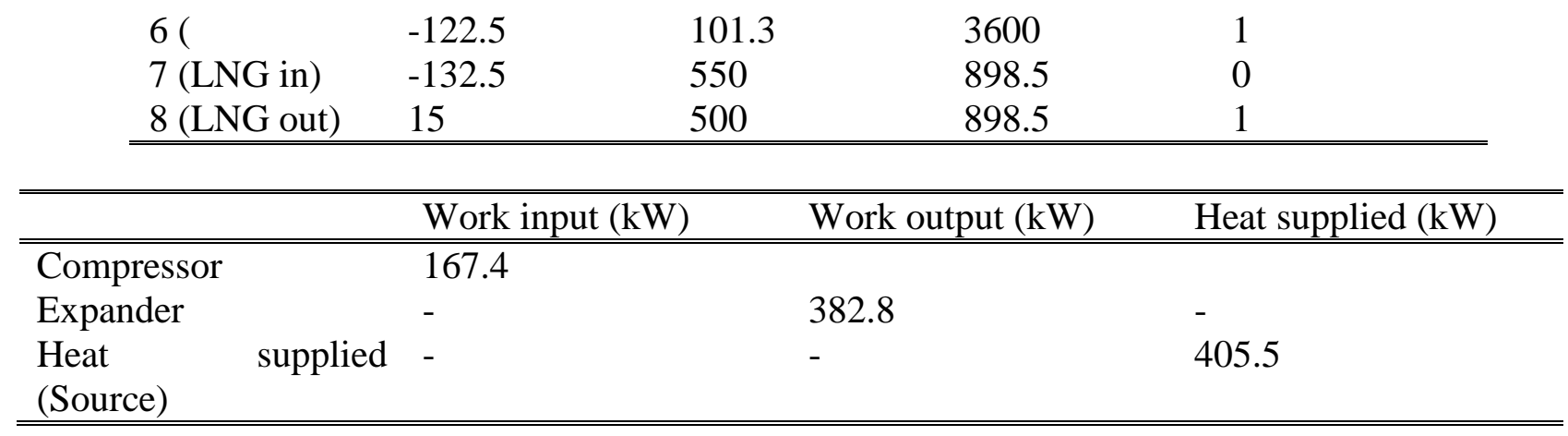

Working fluid: Argon

\begin{tabular}{lllll}
\hline \hline & Temperature $\left({ }^{\circ} \mathrm{C}\right)$ & Pressure $(\mathrm{kPa})$ & Mass flow $(\mathrm{kg} / \mathrm{hr})$ & Vapor fraction \\
\hline \hline 1 & 133.2 & 800 & 3600 & 1 \\
2 & 326.3 & 800 & 3600 & 1 \\
3 & 800 & 800 & 3600 & 1 \\
4 & 347.4 & 101.3 & 3600 & 1 \\
5 & 153.2 & 101.3 & 3600 & 1 \\
6( & -122.5 & 101.3 & 3600 & 1 \\
7 (LNG in) & -132.5 & 550 & 682.6 & 0 \\
8 (LNG out) & 15 & 500 & 682.6 & 1 \\
\hline \hline
\end{tabular}

\begin{tabular}{|c|c|c|c|c|}
\hline & & "Work input (kW) & Work output (kW) & Heat supplied (kW) \\
\hline Compressor & & 132.91 & 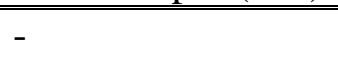 & - \\
\hline Expander & & - & 235.72 & - \\
\hline $\begin{array}{l}\text { Heat } \\
\text { (Source) }\end{array}$ & supplied & - & - & 247.02 \\
\hline
\end{tabular}

Working fluid: Air

\begin{tabular}{|c|c|c|c|c|}
\hline & Temperature $\left({ }^{\circ} \mathrm{C}\right)$ & Pressure $(\mathrm{kPa})$ & $\begin{array}{ll}\begin{array}{l}\text { Mass } \\
(\mathrm{kg} / \mathrm{hr})\end{array} & \text { flow } \\
\end{array}$ & $\begin{array}{l}\text { Vapor } \\
\text { fraction }\end{array}$ \\
\hline $\bar{~} 1$ & 444.3 & 800 & 3600 & $\bar{~} 1$ \\
\hline 2 & 448.2 & 800 & 3600 & 1 \\
\hline 3 & 800 & 800 & 3600 & 1 \\
\hline 4 & 468.3 & 101.3 & 3600 & 1 \\
\hline 5 & 64.3 & 101.3 & 3600 & 1 \\
\hline 6( & -122.5 & 101.3 & 3600 & 1 \\
\hline 7 (LNG in) & -132.5 & 550 & 872.9 & 0 \\
\hline 8 (LNG out) & 15 & 500 & 872.9 & 1 \\
\hline
\end{tabular}

\begin{tabular}{|c|c|c|c|c|}
\hline & & Work input $(\mathrm{kW})$ & Work output (kW) & "Heat supplied $(\mathrm{kW})$ \\
\hline Compressor & & 162.6 & & \\
\hline Expander & & - & 370.9 & - \\
\hline $\begin{array}{l}\text { Heat } \\
\text { (Source) }\end{array}$ & supplied & - & - & 392.6 \\
\hline
\end{tabular}


Equipment specifications assumed for model

\begin{tabular}{ll}
\hline \hline Isentropic efficiency of turbine & $75 \%$ \\
Isentropic efficiency of turbine & $75 \%$ \\
Pressure drop across heat source & $0 \mathrm{kPa}$ \\
Pressure drop across LNG heat exchanger & $50 \mathrm{kPa}$ \\
Minimum approach of heat exchangers & $20 \mathrm{C}$ \\
\hline \hline
\end{tabular}

\section{REFERENCES}

[1] Saeid M, John YM, Jaleel VV. Handbook of liquefied natural gas, Gulf professional publications; 2013

[2] Easwaran N. K, Rijo JT, Majo D. "Regasification of LNG: Comparative analysis of different techniques", National Symposium of Cryogenics (NSC 25), Central University, Hyderabad, December 2014.

[3] Marquez A, Bruo J, Coronas A. Cold recovery from LNG-regasification for polygeneration applications. Appl Thermal Engg 132 (2018) 463-478.

[4] Marco B, Juan CB, Alberto C, Gabriele F. Analysis of different combined cycles and working fluids for LNG exergy recovery during regasification, Energy 2018;159: 373-384.

[5] Satrio D, Utama KP, Mukhtasor. The influence of time step setting on the CFD simulation result of vertical axis tidal current turbine, Journal of Mechanical Engineering and Sciences; 2018:12 (1) 3399-3409

[6] Inkyu L, Jinwoo P, Il M. Conceptual design and exergy analysis of combined cryogenic energy storage and LNG regasification processes: Cold and power integration, Energy 2017;(140) 106-115.

[7] Diogo AS, Marina FS, Paulo SS. Performance analysis of a CCGT power plant integrated to a LNG regasification process, Journal of Natural Gas Science and Engineering 2015; 23: 112 117

[8] Abidin S, Mohammed I S, Hashim AY, Abdullah N, Hafiz, Masripan N.A.B, Abdullah A. Investigation of thermal characteristics of CNF-based nanofluids for electronic cooling application, Journal of Mechanical Engineering and Sciences 2016; 10 (3): 2336-2349.

[9] Baris BK, Liming X, Swapnil D, Fook HC, Fei D. Cold utilization systems of LNG: A review, Renewable and Sustainable Energy Reviews 2017; 79: 1171-1188

[10] Mosaffa AH, Mokarram NH, Farshi LG. Thermo-economic analysis of combined different ORCs geothermal power plants and LNG cold energy. Geothermics. 2017 Jan 1;65:113-25.

[11] Marco B, Juan CB, Alberto C, Gabriele F. Analysis of different combined cycles and working fluids for LNG exergy recovery during regasification, Energy 2018; 159: 373-384

[12] Sun Z, Xu F, Wang S, Lai J, Lin K. Comparative study of Rankine cycle configurations utilizing LNG cold energy under different NG distribution pressures. Energy. 2017 Nov 15;139:380-93.

[13] Barsali S, Ciambellotti A, Giglioli R, Paganucci F, Pasini G. Hybrid power plant for energy storage and peak shaving by liquefied oxygen and natural gas. Applied Energy. 2018 Oct $15 ; 228: 33-41$.

[14] Sulaiman SA, Inayat M, Basri H, Guangul FM, Atnaw S M, Effect of blending ratio on temperature profile and syngas composition of woody biomass co-gasification, Journal of Mechanical Engineering and Sciences 2016; 10(2): 2176-2186.

[15] García RF, Carril JC, Gomez JR, Gomez MR. Combined cascaded Rankine and direct expander based power units using LNG (liquefied natural gas) cold as heat sink in LNG regasification. Energy. 2016 Jun 15;105:16-24. 
[16] Dhameliya H, Agrawal P. LNG Cryogenic Energy Utilization. Energy Procedia. 2016 Dec 1;90:660-5.

[17] Guoqiang Z, Jiongzhi Z, Yongping Y, Wenyi L. A novel LNG cryogenic energy utilization method for inlet air cooling to improve the performance of combined cycle, Applied Energy 2016; 179: 638-49

[18] Mehrpooya M, Mohammad MM. Conceptual and basic design of a novel integrated cogeneration power plant energy system Source: Energy 2017;127: 516-533

[19] Moghimi M, Khosravian M. Exergy optimization for a novel combination of organic Rankine cycles, Stirling cycle and direct expander turbines, Heat Mass Transfer 2018; 54: 1827-1836

[20] Thomas RJ, Ghosh P, Chowdhury K. Application of exergy analysis in designing helium liquefiers. Energy. 2012 Jan 1;37(1):207-19.

[21] Jason T, Noam L, Na Z. Analysis of thermal cycles and working fluids for power generation in space, Energy conversion and management 2007; 48 (11): 2864-2878.

[22] Bentivoglio F, Tauveron N, Geffraye G, Gentner H. Validation of the CATHARE2 code against experimental data from Brayton-cycle plants. Nuclear Engineering and Design. 2008 Nov 1;238(11):3145-59.

[23] Thomas RJ, Ghosh P, Chowdhury K. Exergy based analysis on different expander arrangements in helium liquefiers. international journal of refrigeration. 2012 Jun 1;35(4):1188-99.

[24] Nordin A, Majid MA. Parametric study on effect of pinch and approach points on heat recovery system generator performance of at a district cooling system, Journal of Mechanical Engineering and Sciences2017; 11(2): 2626-2636.

[25] Tahseen A, Ishak M, Rahman MM. Laminar forced convection heat transfer over staggered circular tube banks: a CFD approach, Journal of Mechanical Engineering and Sciences; 2013:4 418-430. 